\title{
Antibiotic Sensitivity Pattern and Plasmid Profile of Bacteria Isolated from Diabetic Ulcers in Mbano Metropolis, Imo State, Southeastern Nigeria
}

Nwankwo, E. O., Nwagbara, E. E., Onusiriuka, K. N.

Department of Microbiology, College of Natural Sciences, Michael Okpara University of Agriculture, Umudike, Abia State

Corresponding author Email: emmaonwubiko@yahoo.com

\begin{abstract}
The study was undertaken to evaluate the bacteriology and antibiogram of isolates from diabetic patients with chronic foot ulcers in Nigeria. A total of 150 pus samples were collected and processed according to standard aerobic and anaerobic microbiological methods. Antibiogram was done using Kirby-Bauer method. Biofilm tests, ESBL \& AmpC production was conducted using Congo red agar, Double disc synergy test and Cefoxitin disc test respectively. Total number of isolates obtained was 210. The Plasmid profiles of some of the Multi-Drug Resistance (MDR) isolates were carried out using the alkaline lysis method for plasmid extraction and electrophoresis on agarose gel with standard markers. The most frequently isolated aerobic organism in the study was Escherichia coli (32.1\%) while the least occurring was Enterobacter spp (1.57\%). For the anaerobes, Peptostreptococcus spp (40\%) was the highest isolated bacterium. Percentage of Extended Spectrum $\beta$-lactamase (ESBL) producers among $E$. coli isolates was 44\%. Percentages of biofilm formation potential among the isolates were: E. coli (36.8\%), S. aureus (23.1\%) and Proteus vulgaris (4.2\%). Escherichia coli and S. aureus showed considerable levels of resistance to some common antibiotics. No methicilin resistant $S$. aureus was encountered. AmpC producers encountered were Klebsiella pneumonia (10\%) and E. coli $(8.1 \%)$. Post-curring antibiogram tests revealed that nine isolates carried plasmids, suggesting that the mode of resistance may be plasmid mediated.
\end{abstract}

Keywords: Diabetic ulcers, Bacteria, Antibiogram, Plasmid profile.

\section{INTRODUCTION}

Diabetic ulcer is a serious clinico-pathologic outcome of diabetes with recent studies revealing that life time risk of developing a foot ulcer in diabetic patients could be as high as $25 \%$ which leads to proximate and nontraumatic causes of leg amputation (Lipsky, 2004; Ahmed et al., 2006). Presently there is increasing empirical evidence suggesting that diabetes is a risk factor for antibiotic-resistant Streptococcus pneumonia, Methicillin resistant Staphylococcus aureus (MRSA) with basal sensitivity to vancomycin and vancomycin-resistant enterococci as well as ESBL producing Gram negative bacteria and carbapenem-resistant Pseudomonas spp (Lyndmila et al., 2013).

The prevalence of foot infections in persons with diabetes ranges from a lifetime risk of up to $25 \%$ in persons with the disease, to $4 \%$ yearly in patients treated in a diabetic foot center (Singh et al., 2005). In diabetic foot ulcers, various organisms inhabit the wound and in most patients one or more species of organisms multiply in the wound which may lead inexorably to tissue damage. Utilizing a murine chronic wound model, some researchers found that DNA protected $P$. aeruginosa in the wounds of insulin-treated diabetic mice from antibiotic treatment (Watters et al., 2014). Due to common or recurrent infections, diabetic patients have more antibiotic treatments compared with other subjects which can increase the antibiotic resistance rates in the bacteria (Watters et al., 2014). In a study in Malaysia, S. aureus was found to be predominant followed by Klebsiella pneumonia and Pseudominas aeruginosa (Mohanasoundram, 2012). The increased relationship of multidrug resistant (MDR) pathogens with diabetic ulcers, further compounds the problem faced by physicians or surgeons in treating diabetic ulcers without resorting to amputation (Yoga et al., 2006). Infection with MDR pathogens incurs a lot of expenses and leads to delayed hospital stay, and sometimes increases the chances of mortality in diabetic patients. 
Careful selection of antibiotics based on the susceptibility pattern of the isolates from the lesions is most reliable for the proper management of these infections.

Reported cases of diabetic infections which investigated the prevalence of microbes and their associated multi-drug resistance have been published in developed countries. Contrastingly, the bacteriology of diabetic ulcers in Nigeria has not been studied extensively especially in the south-eastern part of the country. This study was designed to identify the common bacterial agents found in foot ulcers of diabetic patients in Imo State and to determine their in vitro susceptibility to routinely used antibiotics.

\section{MATERIALS AND METHODS \\ Study Location}

The study was conducted in Ihitte Uboma town in Imo State. Samples were collected from Madonna Austrian Hospital Ihitte which serves as a referral hospital in the locality.

\section{Study Design}

This is a cross sectional surveillance study.

\section{Study Population and study sample}

The study population comprised of all diabetic patients that reported to Madonna Austrian Hospital Ihitte between June, 2018 and January, 2020. A total of 150 diabetic patients with diabetic foot ulcers were enrolled for the study, out of which 65 patients were on admission while 85 were out-patients. Some of the patients were referrals from other healthcare centres in the neighbouring towns. The collect foot ulcer samples were processed at the Microbiology laboratory of Michael Okpara University, Umudike and Oevent Research Laboratory Uzuakoli Road Umuahia respectively.

Sample collection from the diabetic foot ulcers patients

The surface of the wound was cleaned with physiological saline to avoid skin contaminants. With the aid of two sterile swab sticks, pus samples were collected from the foot ulcers of each diabetic patient. The sample collection was carried out before wound dressing.

Isolation of aerobic bacteria

The swab was inoculated on to blood agar, MacConkey agar and Mannitol Salt agar and incubated at $37^{\circ} \mathrm{C}$ for $24 \mathrm{hrs}$ (Turgeon, 2012). Isolation of anaerobic bacteria

The second swab sample was inoculated in neomycin sulphate blood agar and cooked meat broth immediately. The blood agar plate was incubated anaerobically for $48 \mathrm{hrs}$ at $37^{\circ} \mathrm{C}$ in an anaerobic jar with Gaspak Oxoid BRO038B (Gas Generating Kit). Saccharolytic reaction is shown by reddening of the meat with a rancid smell due to carbohydrate decomposition while proteolytic reaction is shown by blackening of the meat with a very unpleasant smell due to protein decomposition.

Identification of Organisms

The isolates were identified by standard techniques on the basis of their cultural morphology, motility, Gram staining reaction and biochemical properties according to CLSI (2015).

Antibiotic Sensitivity test

Antimicrobial susceptibility testing was performed using the disk diffusion method according to Clinical Laboratory Standard Institute (2015) on Mueller Hinton agar (Hardy Diagnostics, USA). Mueller Hinton culture plates were inoculated using a sterile cotton wool swab dipped into an overnight growth suspension of the test organism prepared to the density of 0.5 McFarland standard. The antibiotics tested were cotrimoxazole $(25 \mu \mathrm{g})$, levofloxacin $(20 \mu \mathrm{g})$, streptomycin $(30 \mu \mathrm{g})$, ciprofloxacin $(10 \mu \mathrm{g})$, amoxicillin (10 $\mathrm{gg})$, amoxicillin/clavulanate $(30 \mu \mathrm{g})$, gentamicin $(10 \mu \mathrm{g})$, perfloxacin $(10 \mu \mathrm{g})$, ofloxacin $(10 \mu \mathrm{g})$, ceftriaxone $(30 \mu \mathrm{g})$, ceftazidime $(30 \mu \mathrm{g})$, erythromycin $(30 \mu \mathrm{g})$. After overnight incubation, examination of the control and test plates were carried out to ensure the growth is semi- confluent. Using a ruler on the underside of the plate of each zone of inhibition was measured in $\mathrm{mm}$. Escherichia coli ATCC 25922 was used as the control strain for this study. This organism was obtained from Aminu Kano Teaching Hospital (AKTH), Kano.

\section{ESBL Screening and confirmation}

The isolates were tested against third generation cephalosporins (Cefpodoxime, cefotaxime, and ceftrixone) using the WHO modified Kirby Bauer diffusion method (2003). Zone diameters were interpreted using the revised Clinical Laboratory Standard Institute document (2015). Isolates with reduced susceptibility to cefpodoxime $(<17 \mathrm{~mm})$, cefotaxime $(<27 \mathrm{~mm})$ and ceftriaxone $(<25 \mathrm{~mm})$ were considered to be possible ESBL producers. 
Phenotypic Confirmation Test was carried out using Double Disc Synergy test. Disc containing the standard $10 \mu \mathrm{g}$ of cefpodoxime and the $30 \mu \mathrm{g}$ of ceftazidime/ ceftriaxone was placed $15 \mathrm{~mm}$ apart (edge to edge) with amoxicillin-clauvlanic acid disc containing $10 \mu \mathrm{g}$ of the latter compound mounted exactly at their center. After $16-20$ hours of incubation at $35^{\circ} \mathrm{C}$ any enhancement of the zone of inhibition between a beta-lactam disk and that containing the $\beta$-lactamase inhibitor is indicative of the presence of an ESBL (Jacoby et al., 2004).

\section{Screening for AmpC $\boldsymbol{\beta}$-lactamase}

Screening for AmpC B-lactamase production was done by placing a cefoxitin disk $(30 \mu \mathrm{g})$ on Mueller-Hinton agar. Isolates showing an inhibition zone diameter of $<18 \mathrm{~mm}$ were considered positive on the screening.

Amp C Detection test

A 0.5 McFarland suspension of multidrug resistant bacteria was inoculated on the surface of a MHA plate. A 30 $\mathrm{gg}$ cefoxitin disc (Oxoid, England) was placed on the inoculated surface of the agar. A sterile plain disc inoculated with several colonies of the test organism was placed beside the cefoxitin disc almost touching it, with the inoculated disk face in contact with the agar surface. The plates were incubated at $37^{\circ} \mathrm{C}$ for 24 hours. After incubation, the plates were examined for either an indentation or a flattening of the zone of inhibition, indicating enzymatic inactivation of cefoxitin (negative result) (CLSI, 2015).

Test for Methicillin Resistant Staphylococcus. Susceptibility to cefoxitin was determined by the Disk Diffusion method on Mueller-Hinton agar plates using a bacterial suspension with the turbidity adjusted to a 0.5 McFarland standard. Plates were incubated at $35^{\circ} \mathrm{C}$ for 24 hrs. Results were interpreted according to CLSI (2013) guidelines. The interpretive criteria for cefoxitin were: S. aureus, sensitive $\geq 22 \mathrm{~mm}$, resistant $\leq 21 \mathrm{ug} / \mathrm{ml}$; Coagulase Negative Staphylococcus (CoNS), sensitive $\geq 25 \mathrm{~mm}$, resistant $\leqslant 24 \mathrm{~mm}$.

Test for Biofilm Formation Potential

This was done by the Congo Red Agar Method. Blood agar base supplemented with sucrose and Congo red was used. Plates were inoculated with the tested isolates and incubated aerobically for $24 \mathrm{hrs}$ at $37^{\circ} \mathrm{C}$. Positive result was indicated by black colonies with a dry crystalline consistency. Non slime producers usually remained pink (Mathur et al., 2006).

UMYU Journal of Microbiology Research

\section{Plasmid Extraction}

Plasmid extraction was done following the method described by Birnboim, et al., (1979). This analysis was carried out using the alkaline lysis method and gel electrophoresis.

\section{Plasmid Curing}

Ten millilitres of each bacterial culture inoculated into peptone water and incubated for $24 \mathrm{hrs}$ was introduced into a set of 20 test tubes, respectively. Ethidium bromide in various concentrations of $0,20,50,100,150$, $200,250,300,350,400,450,500,550$, $600,650,700,750$ and $800 \mu \mathrm{l} / \mathrm{ml}$ were then introduced accordingly into the test tubes and incubated at $37^{\circ} \mathrm{C}$ for $24 \mathrm{hrs}$ to determine the sub-lethal concentrations of ethidium bromide. After $24 \mathrm{hrs}$ of incubation, $1 \mathrm{ml}$ aliquot from each test tube was inoculated onto nutrient agar plates and incubated, after which colonies were selected and inoculated onto freshly prepared Muller Hinton agar plates. Then, antibiotic discs of prior resistance were aseptically introduced into the plates, ensuring that the discs made appropriate contact with the surface of the agar. These were incubated for $24 \mathrm{hrs}$ at $37^{\circ} \mathrm{C}$ after which plates were examined for cured colonies (Raghada et al., 2013).

\section{RESULTS}

Table 1 shows the age and sex distribution of Diabetic ulcer patients. Of the 150 patients enrolled for this study, 90 $(60 \%)$ were male and 60 (40\%) were female. Their ages ranged from 41 to $>90$ and the highest number of patients were found in the age group of $61-70$ years $(28 \%)$, followed by those the aged of $81-90$ years $(20.6 \%)$ then the age groups $41-50(9.3 \%)$ and $>90(9.3 \%)$.

Table 2 shows the distribution of aerobic and anaerobic isolates. A total 210 isolates were obtained from this study out of which 137 (65.5\%) were Gram negative, 53 (25.5\%) were Gram positive and 20 (9.5\%) were anaerobes. The most frequently isolated organism in this study was Escherichia coli (32.1\%), and the least was Enterobacter spp (1.57\%) for the aerobes. The anaerobes, Peptococcus spp (15\%), Peptostreptococcus spp (40\%), Bacteroides spp (30\%) and Fusobacterium spp (15\%).

Table 3 shows the distribution of organisms with biofilm formation, betalactamase producing potentials and AmpC producers. The percentage of biofilm forming organisms is as follows: $E$ coli (36.8), $S$ aureus (23.1\%), Klebsiella spp (12.6\%), P. aeruginosa (8.4\%), P. mirabilis, COANS (7.3\%) - $1 d$. vulgaris at (4.2\%). It shows the 40 www.ujmr.umyu.edu.ng 
percentage of Extended Spectrum Betalactamse (ESBL) as follows: $E$ coli (44\%), Klebsiella spp and $P$. mirabilis $(17 \%)$ each, $P$. aeruginosa $(15 \%)$ and $P$. vulgaris $(4 \%)$. Also, Table 3 the AmpC producers encountered as Klebsiella spp (28.5\%) and E. coli (71.4\%).

Table 4 shows the antibiogram for Gram negative and Gram positive isolates. $E$ coli recorded the highest sensitivity rate with Ciprofloxacin (57.3\%) and Gentamicin (40.9\%) (Table 4). Similarly, Klebsiella spp recorded higher sensitivity rate of $70 \%$ to Ciprofloxacin and 55\% to Perfloxacin and Ofloxacin (Table 4). The antibiogram for the Gram-positive organisms indicated that organisms like Staphylococcus aureus and
Coagulase negative Staphylococcus spp (COANS) were sensitive to Ofloxacin at the rate of $63 \%$ and $100 \%$ respectively. Enterococcus spp was $100 \%$ sensitive to Streptomycin while COANS showed $100 \%$ sensitivity to Ofloxacin, Amoxil and Streptomycin (Table 4). Citrobacter spp was $100 \%$ sensitive to Perfloxacin, Ciprofloxacin, Ofloxacin and Gentamicin while Enterobacter spp was $100 \%$ sensitive to Ofloxacin and Pefloxacin (Table 4).

Table 5 shows the distribution of plasmids and their molecular weight. It also reveals the resistance pattern of isolates before and after curing.

Table 1: Age and Sex Distribution of Diabetic Ulcer Patients

\begin{tabular}{lcccc}
\hline Age (Years) & No. examined & Male & Female & Percentage (\%) \\
\hline $41-50$ & 14 & 7 & 7 & 9.3 \\
$51-60$ & 21 & 11 & 10 & 14 \\
$61-70$ & 42 & 32 & 10 & 28 \\
$71-80$ & 28 & 18 & 10 & 18 \\
$81-90$ & 31 & 16 & 15 & 20.6 \\
$>90$ & 14 & 6 & 8 & 9.3 \\
\hline Total & 150 & 90 & 60 & \\
\hline
\end{tabular}

Table 2: Distribution of aerobic and anaerobic Isolates

\begin{tabular}{|c|c|c|}
\hline \multicolumn{3}{|l|}{ Aerobic Isolates } \\
\hline Organisms & Number of Occurence & Percentage (\%) \\
\hline Klebsiella spp & 20 & 10.5 \\
\hline E coli & 61 & 32.1 \\
\hline P. mirabilis & 20 & 10.5 \\
\hline Enterobacter spp & 3 & 1.57 \\
\hline COANS & 10 & 5.2 \\
\hline S. aureus & 30 & 15.7 \\
\hline P. aeruginosa & 19 & 10 \\
\hline E. faecalis & 8 & 4.2 \\
\hline Strept spp & 5 & 2.6 \\
\hline Citrobacter spp & 3 & 1.57 \\
\hline Total & 190 & \\
\hline \multicolumn{3}{|l|}{ Anaerobic Organisms } \\
\hline Peptococcus spp & 3 & 15 \\
\hline Peptostreptococcus spp & 8 & 40 \\
\hline Bacteroides spp & 6 & 30 \\
\hline Fusobacterium spp & 3 & 15 \\
\hline Total & 20 & \\
\hline
\end{tabular}

CONS = Coagulase Negative Staphylococci 
UJMR, Volume 6 Number 1, June, 2021, pp 38 - $46 \quad$ ISSN: 2616 - 0668

Table 3: Distribution of Organisms with Biofilm Formation, Beta-lactamase producers and AmpC producers Number Positive (Percentage)

\begin{tabular}{lllll}
\hline Organisms & $\begin{array}{l}\text { Number } \\
\text { Isolated }\end{array}$ & $\begin{array}{l}\text { Biofilm forming } \\
\text { potential }\end{array}$ & $\begin{array}{l}\text { Beta-lactamase } \\
\text { producers }\end{array}$ & $\begin{array}{l}\text { AmpC } \\
\text { producers }\end{array}$ \\
\hline Klebsiella spp & 20 & $12(12.6 \%)$ & $8(17 \%)$ & $2(28.5 \%)$ \\
E. coli & 61 & $35(36.8 \%)$ & $20(44 \%)$ & $5(71.4 \%)$ \\
P. vulgaris. & 11 & $4(4.2 \%)$ & $2(4 \%)$ & Nil \\
P. mirabilis & 20 & $7(7.3 \%)$ & $8(17 \%)$ & Nil \\
Enterobacter spp. & 3 & $\mathrm{Nil}$ & $\mathrm{Nil}$ & Nil \\
CoNS & 10 & $7(7.3 \%)$ & $\mathrm{Nil}$ & Nil \\
S.aureus & 30 & $22(23.1 \%)$ & $\mathrm{Nil}$ & $\mathrm{Nil}$ \\
P. aeruginosa. & 19 & $8(8.4 \%)$ & $7(15 \%)$ & Nil \\
E. faecalis & 8 & $\mathrm{Nil}$ & $\mathrm{Nil}$ & $\mathrm{Nil}$ \\
Streptococcus spp. & 5 & $\mathrm{Nil}$ & $\mathrm{Nil}$ & $\mathrm{Nil}$ \\
Citrobacter spp. & 3 & $\mathrm{Nil}$ & $\mathrm{Nil}$ & $\mathrm{Nil}$ \\
\hline
\end{tabular}

Table 4: Antibiogram result of the bacterial isolates

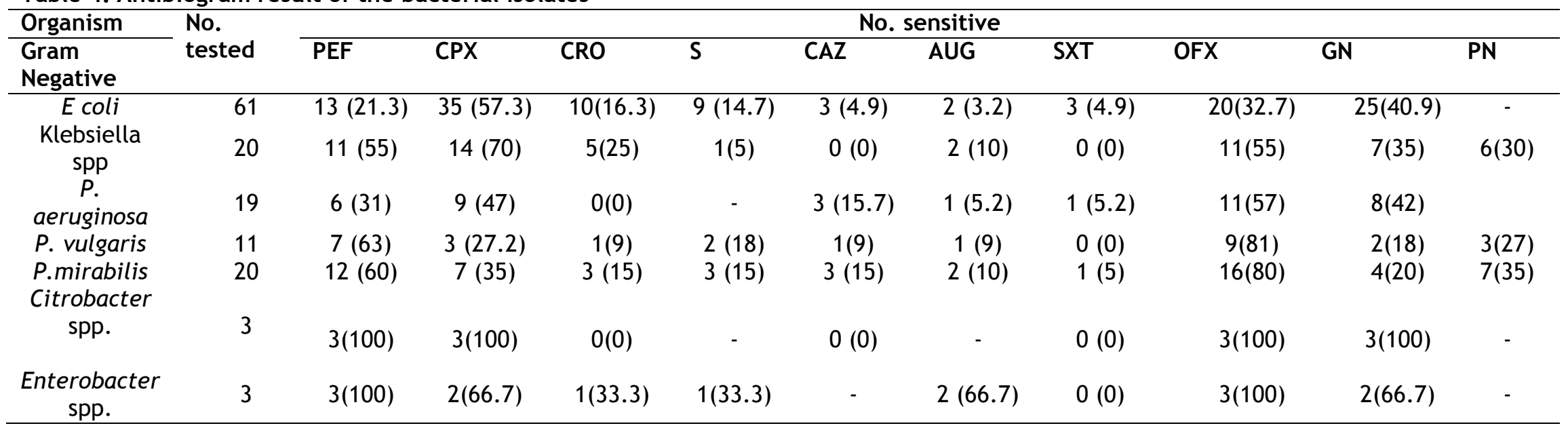


Table 4 continue

\begin{tabular}{|c|c|c|c|c|c|c|c|c|c|c|c|c|}
\hline \multirow{2}{*}{ Gram positive } & \multirow{2}{*}{$\begin{array}{c}\text { No. } \\
\text { tested }\end{array}$} & \multicolumn{11}{|c|}{ No. sensitive } \\
\hline & & PEF & LEV & CPX & OFX & ERY & GN & APX & AUG & AM & $\mathbf{S}$ & $\mathbf{R}$ \\
\hline S. aureus & 30 & $\begin{array}{l}10 \\
(33.3)\end{array}$ & $18(60)$ & $15(50)$ & $\begin{array}{l}19 \\
(63)\end{array}$ & $15(50)$ & $21(70)$ & $0(0)$ & $9(30)$ & $0(0)$ & $5(16)$ & $5(16)$ \\
\hline $\begin{array}{l}\text { Streptococcus } \\
\text { spp }\end{array}$ & 5 & $0(0)$ & $0(0)$ & $1(20)$ & $3(60)$ & $3(60)$ & $1(20)$ & $1(20)$ & $0(0)$ & $1(20)$ & $0(0)$ & $2(40)$ \\
\hline CoaNs & 10 & $0(0)$ & $0(0)$ & 7 (70) & $\begin{array}{l}10 \\
(100)\end{array}$ & $9(90)$ & $5(50)$ & $0(0)$ & $0(0)$ & $\begin{array}{l}10 \\
(100)\end{array}$ & $\begin{array}{l}10 \\
(100)\end{array}$ & $8(80)$ \\
\hline $\begin{array}{l}\text { Enterococcus } \\
\text { spp }\end{array}$ & 8 & $0(0)$ & $0(0)$ & $1(12.5)$ & $\begin{array}{l}3 \\
(37.5)\end{array}$ & $1(12.5)$ & $1(12.5)$ & $1(12.5)$ & $1(12.5)$ & $0(0)$ & $\begin{array}{l}8 \\
(100)\end{array}$ & $1(12.5)$ \\
\hline
\end{tabular}

KEY: PEF= Perfloxacin, CPX=Ciprofloxacin, CRO = Ceftriaxone, $\mathrm{S}=$ Streptomycin, CAZ = Ceftazidime, AUG=Amoxicillin-clavulanate,

OFX=Ofloxacin, LEV=Levofloxacin, ERY= Erythromycin, APX= Ampicillin, AM=Amoxicillin, SXT= Septrin, GN=Gentamicin, PN=Ampicillin, CoNS = Coagulase Negative Staphylococci, Strept. Spp = Streptococcus spp, AM= Amoxicillin, R=Rifampicin, APX= Ampiclox

Table 5: Distribution of Plasmids among Resistant Isolates, Cured Plasmids and Antibiotic Resistance

\begin{tabular}{llll}
\hline Organisms & Base pair (bp) & Resistance before curing & Resistance after curing \\
\hline E1 & & PEF,CPX,CAZ,CRO,S,GN & \\
E2 & CPX,S,OFX,CRO,CAZ,AU & OFX, CPX, PEF \\
E3 & 23130 & OFX,CPX,CAZ,CRO,PEF,GN & CRO,OFX,CAZ \\
E4 & 23130 & OFX,CAZ,CRO,CPX,AU,S & CRO,AU,OFX, \\
E5 & 23130 & CAZ,CRO,OFX,GN,AU,PEF & CAZ,CRO,PEF,OFX \\
E6 & 23130 & CRO,CAZ,OFX,GN,AU,PEF & CRO,CAZ \\
E7 & 23130 & CPX,S,CRO,CAZ,PEF,GN & S, CPX, PEF \\
E8 & 23130 & CRO,CAZ,CPX,PEF,AU,S & OFX,CPX,CRO, \\
E9 & OFX,CPX,CRO,CAZ,PEF,S & CAZ, PEF, S \\
E10 & 23130 & CAZ,CRO,OFX,PEF,AU,S & CRO,OFX,S \\
E11 & 23130 & PEF,AU,CPX,CAZ,CRO,GN & PEF,CRO, CPX \\
E12 & CRO,CAZ,AU,PEF,CPX,S & \\
E13 & 23130 & CPX,PN,OFX,CRO,CAZ, & \\
E14 & & CRO.CPX,PN,GN,PEF,S & \\
E15 & & CAZ,CRO,OFX,CPX,AU,S. & \\
\hline
\end{tabular}

43 


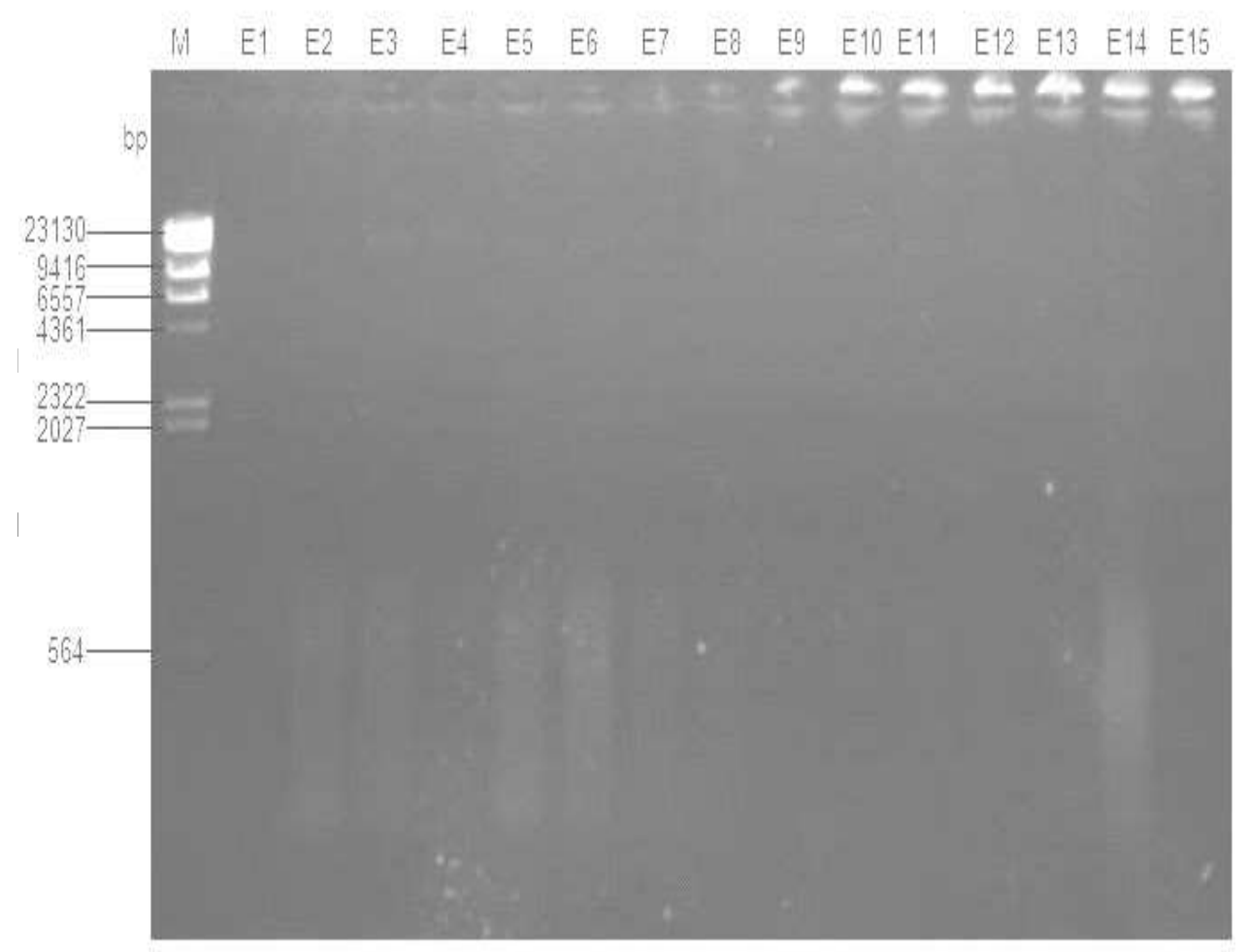

\section{DISCUSSION}

The prevalence of diabetic ulcers among male subjects was found to be $60 \%$ and $40 \%$ in females. This may be due to higher level of outdoor activity among males compared to females. This corresponds with the findings of some researchers as they indicated the preponderance of diabetes among males compared to females (Lilian et al., 2015; Mohanasoundram, 2012; Nwachukwu et al., 2009). Majority of the patients were in the age group of 61-70, suggesting that age could be a risk factor as the elderly are naturally predisposed to infections. This agrees with a report in South India by Viswanathan et al. (2002).

The study findings indicated that Gram negative microbes were the predominant pathogens isolated with 65\% Gram negative, 25\% Gram positive and $9.5 \%$ anaerobes. A similar result was documented in Malaysia revealing more Gram-negative bacteria (52\%) than Gram positive bacteria (45\%) (Raja, 2007). In addition, this agrees with the report of Lilian et al. (2015) but contradicts with that of Mohanasoundram (2012) whose study showed S. aureus as the most prevalent followed by $E$ coli, Klebsiella spp, Pseudomonas aeruginosa, Enterococcus faecalis, and Non Fermenting Gram Negative Bacteria
(NFGNB).

The Gram-negative organisms isolated from this study were sensitive to perfloxacin ciprofloxacin, ofloxacin and gentamycin. The Gram-positive organisms were susceptible to ofloxacin, erythromycin and gentamicin. This is consistent with the findings in Kumasi, Ghana where most of the Gram-negative organisms were sensitive to ciprofloxacin and gentamicin (Brenyah et al., 2014). Similarly, Gram positive organisms like S. aureus and CONS were observed to be highly sensitive to ofloxacin. This sensitivity pattern agrees with the findings of Lilian et al. (2015).

Five out of seven Gram negative organisms isolated from this study were observed to be ESBL producers. Among the Gram negative, E. coli ( a t $44 \%$ ) had the highest number of ESBL producers while, Proteus vulgaris had the least at $4 \%$. This is in accordance with the study of Bansal et al. (2008) and Shashikala et al. (2016) who reported a high level of ESBL production among Ecoli isolates. However, this contradicts with the work of Samir et al. (2009) who reported Proteus spp as having the highest ESBL producing potential from their study. This variance could be associated with the difference in sample size as Samir et al. (2009) used 75 patients for their study. The increasing prevalence of ESBL producing organisms is 
disturbing because of the problems associated with antibiotic prescription.

Recent studies have shown that biofilm associated microorganisms can be up to 1000 times more resistant to antibiotics than free floating planktonic bacteria. In the present study, seven organisms were biofilm formers. $E$. coli had the highest biofilm forming potential followed by $S$. aureus, Klebsiella spp, $P$. aeruginosa, $P$. mirabilis, CONS and $P$. vulgaris. This result agrees with that of Gordon et al. (2008) on the biofilm forming nature of Staphylococci. This result disagrees with the study of Asima et al. (2015) who reported S .aureus as having the highest potential for biofilm formation followed by $P$. aeruginosa, Citrobacter spp and Ecoli. The unusual number of biofilm forming E.coli may be as a result of the high prevalence rate of $E$. coli in this study.

This study reports a high level of AmpC production in K. pneumonia and Ecoli. This is at variance with the report from researches at Kolkata which recorded a high level of AmpC production in $P$. aeruginosa (Subha et al., 2003; Suranjana et al., 2005). Agarose gel electrophoresis of plasmid DNA in this study It is recommended that ESBL producers be subjected to further molecular procedures to define their various types and transformation

\section{REFERENCES}

Ahmed, A. and Choudhury, M.K. (2006). The role of orthopedic surgery and rehabilitation in the management of diabetic foot. Journal Diabetes Endocrinology. 34:12.

Asima, B., Mir Mohammad, N.H., Janani, R. and Sathyabheemarao, S. (2015). Spectrum of bacteria associated with diabetic foot ulcer and biofilm formation: A prospective study. Academy of Management Journal 8(9):280-285.

Bansal, E., Garg, A., Bhatia, S., Attri, A.K. and Chander, J. (2008). Spectrum of microbial flora in diabetic foot ulcers. Indian Journal of Pathology and Microbiology51(2):204-208.

Birnboim, H.C. and Doly, J. (1979). A rapid alkaline extraction procedure for screening recombinant plasmid DNA. Nucleic Acids Research7(6):1513-152391399.

Brenyah, R. C., Ephraim, R., Jnr, B. A. and Asamoah, J. (2014). Bacterial Profile of Diabetic ulcers of patients visiting a specialist Diabetic Clinic at komfo Anokye

UMYU Journal of Microbiology Research showed that nine out of fifteen samples contained plasmids. Hence, the resistance is plasmid mediated because upon re-exposure of the isolates to antibiotics after plasmid curing, they were observed to be sensitive.

CONCLUSION

This study established the presence of ESBL and AMPC production among biofilm forming bacterial isolates obtained from samples of diabetic patients with foot ulcers. This is of great public health concern as this could contribute to the resistant of these bacterial pathogens to antibiotic like carbapenems.

\section{RECOMMENDATIONS}

Regular studies of the antibiotic susceptibility pattern of diabetic ulcer isolates commonly observed in Mbano will guide clinical judgment and sustain veritable antibiotic prescriptions. Discoveries from such surveys will illuminate the current knowledge on multi drug resistant isolates and proffer solutions about the right choice of antibiotics. The detection of ESBL producers, AmpC producers, Biofilm forming organisms and plasmids are vital.

studies are encouraged to better understand the dynamics of multidrug resistance.

Teaching Hospital Kumasi Ghana. British Journal of Medicine and Medical Research. 4(27):4501-4510.

Clinical and Laboratory Standards Institute (CLSI) (2013). Performance Standards for Antimicrobial Disk Susceptibility Tests; Approved Standard, $11^{\text {th }}$ Edition; West Valley Road, Suite 2500, Wayne, Pennsylvania 19087 USA. M02-A11

Clinical and Laboratory Standards Institute (CLSI) (2015). Performance Standards for Antimicrobial Disk Susceptibility Tests; Approved Standard, $12^{\text {th }}$ Edition; West Valley Road, Suite 2500, Wayne, Pennsylvania 19087 USA.M02-A11

Gordon, R.J. and Lowy, F.D. (2008). Pathogenesis of methicillin resistant Staphylococcus aureus infection. Clinical Infectious Diseases 1:465350-9.

Jacoby, G.A. and Mederios, A. A. (2004). More extended spectrum B-lactamases the CTX-Menzymes. Antimicrobial Agents and Chemotherapy48: 1-14.

45 www.ujmr.umyu.edu.ng 
Lilian, A., Fokunang, N.C., Elias, N.N., Emmanuel, K.T. and Armel, H.N. (2015). Bacteriology of Diabetic Foot Ulcers with Reference to Multidrug Resistance Strains at the Yaounde Central Hospital. Journal of Diseases and Medicinal Plants1(4):5358.

Lipsky, B.A. (2004) Medical treatment of diabetic foot infections. Clinical Infectious Disease 39:104-114.

Lyndmila, B. and Ivan, M. (2013). Antibiotic Resistant rates in causative agents of infectionsinDMpatients. Risingconcerns.Ex pertReviewofAntiinfectioustherapy11(4).114-20.

Turgeon M. L. (2012). Linne and Rinnessgrud's Clinical Laboratory Science. Mosby Elsevier: 53-54.

Mathur, T., Singhal, S. Khan, S., Upadhyay, D. J., Fatma, T. and Rattan, A. (2006). Detection of biofilm formation among the clinical isolates of Staphylococci: An evaluation of three different screening methods. Indian Journal of Medical Microbiology 24(1):25-29.

Mohanasoundram, K. M. (2012). The Microbiological Profile of Diabetic Foot Infections. Journal of Clinical and Diagnostic Research, 6 (3): 409-411.

Nwachukwu, N.C., Orji, F.A. and Udora, E.C. (2009). Bacteriological evaluation of diabetic ulcers in Nigeria. African Journal of Diabetes Medicine, D1-416.

Raja, N.S. (2007). Microbiology of diabetic foot infections in a teaching hospital in Malaysia: A retrospective study of 194 cases. Journal of Microbiology, Immunology and Infection, 40:39-44.

Samir, P., Lovely, B., Ashraf, J.J. and Ashraful, H.A. (2009). Bacteriological Study of Diabetic Foot Infection in An Urban Tertiary Care Hospital of Dhaka City. Ibrahim Medical College Journal, 3(2):5054.

Shashikala,V., Farman, A., Narendranath, L. and Joseph, M. (2016). Diabetic foot ulcer and biofilm formation. International Journal of Biomedical and Advance Research, 7(9):428-433.

Singh, N., Armstrong, D.G. and Lipsky, B.A. (2005). Preventing foot ulcers in patients with diabetes. JAMA. 293:217-2.
Subha, A., Renuka, D.V. and Ananthan, S. (2003). AmpC B-lactamase producing multidrug resistant strains of Klebsiella spp. \& Escherichia coli isolated from children under five in Chennai. Indian Journal of Medical Research, 117:13-18.

Suranjana, A. and Manjusri, B. (2005). AmpC lactamase producing bacterial isolates from Kolkata Hospital. Indian Journal of Medical Research, 122:224-233.

Viswanathan, V., Jasmine, J.J., Snehalatha, C. and Ramachandran, A. (2002). Prevalence of pathogens indiabetic foot infection in South Indian type 2 diabetic patients. Journal of Association of Physicians India, 50:1013-6.

Watters, C., Everett, A., Haley, C., Clinton A. and Rumbaugh K. P. (2014). Insulin treatment modulates the host immune system to enhance Pseudomonas aeruginosa wound infections. Infect Immun 82(1):92-100.

World Health Organization (WHO) (2003). "Modified Kirby-Bauer method in: Basic laboratory procedures in clinical bacteriology" (2 ${ }^{\text {nd }}$ Edition). 109-116.

Yoga, R., Khairul, A., Sunita, K. and Suresh, C. (2006). Bacteriology of diabetic foot lesions. Medical Journal of Malaysia, 61:14-6. 